\title{
Exploring the Extrinsic and Intrinsic Reading Motivations among Malaysian ESL Undergraduates
}

\author{
Farina Tazijan, Rofiza Aboo Bakar, Nor Fazlin Mohd Ramli
}

\begin{abstract}
Purpose of Study: Reading for pleasure is scarce among today's undergraduates. It is believed that undergraduates read books because of their grades and reading not for pleasure. Undergraduates distinguish reading as a chore that they must take upon to excel academically. This paper sets out to conduct a preliminary study of reading motivations among Malaysian undergraduates of English as Second Language Learners.

Methodology: A survey was carried out among UiTM undergraduates using the Reading Motivation Questionnaire $(R M Q)$ to investigate their reading motivation towards extensive reading narratives.

Results: Results revealed that there were 11 elements of reading motivation of the intrinsic and extrinsic motivation dimensions among young adults. Reading efficacy, reading challenge, reading curiosity, reading involvement, the importance of reading, reading work avoidance, competition in reading, recognition for reading. reading for grades and social reasons for reading and compliance were assessed. The results revealed the importance of reading motivation in second language learners

Implications/Applications: It is hoped by identifying the relationship of reading motivation will help in fostering a culture of reading among second language young adult readers.
\end{abstract}

Index Terms: Reading Motivation, Young Adults' Engagement; Reading Motivation Questionnaire (RMQ), Intrinsic Motivation, Extrinsic Motivation, English As A Second Language.

\section{INTRODUCTION}

With the advancement of technology, reading habit is still seen as one of the least interests that Malaysian students have acquired. According to Zurina (1), Malaysians still do not cultivate the reading habit. Malaysians roughly read only about eight to twelve books a year as reported in 2010 (National Library of Malaysia, 2010). Imran Ariffin (2010) states that this number is worrisome as even though graduates of today have higher interests in reading, however they still do not adopt reading as a habit. This is further supported by Abd Wahab (1995) who claims students' failure to instill reading habit is a concerned. In addition, proficient students nowadays do not read for enjoyment (Safiah, 1990). In fact, students assumed reading as a chore to excel academically. In the ESL context, early experience of reading second language

Revised Manuscript Received on September 22, 2019

Farina Tazijan, Senior Lecturer, Akademi Pengajian Bahasa, Universiti Teknologi MARA (UiTM), Pulau Pinang, Malaysia. farina762@uitm.edu.my

Rofiza Aboo Bakar, Senior Lecturer, Akademi Pengajian Bahasa, Universiti Teknologi MARA (UiTM), Pulau Pinang, Malaysia.

Nor Fazlin Mohd Ramli, Senior Lecturer, Akademi Pengajian Bahasa, Universiti Teknologi MARA (UiTM), Shah Alam, Malaysia. materials could influence the attitudes towards reading (2). She also added that students will continue to engage the same attitude that they have adopted towards reading in a second language as they advance to the development stages of reading. Furthermore, students in the English language classroom has different cultures and backgrounds which provide various types of student motivations in reading (Grabe, 2003).

At the tertiary level, reading habit is crucial to students. Nevertheless, according to Tan, Pandian (3) Malaysian tertiary students are unwilling readers of English texts, a situation that can hinder the progress of their English proficiency. He further elaborated by stating that in any ESL/EFL reading program, it is essential to provide materials for lower proficiency students for the students to understand the text.

It is a known fact that reading gives a lot of benefit however in Malaysia reading remains an unpopular habit. According to Abidin, Pour-Mohammadi (4), the National Literacy Survey in 2005 reported that Malaysians read just two books per year. Meanwhile, Shahriza Abdul Karim and Hasan (5) noted that the Malaysian National Library in 2006 found a decline in the nation's literacy rate. According to Pandian (6) $80 \%$ of Malaysian undergraduates are unenthusiastic readers of English and Malay materials and read for the purpose to pass their exam. This situation matter of a lack of reading in English among undergraduates is still a concerned as extensive reading still fails to be cultivated among Malaysian undergraduates.(Musa, Lie (7). Similarly, a recent study done by Nik, Zakaria (8) reported that undergraduates in public universities have low reading motivation and read for the sake of passing their examinations only.

\section{LITERATURE REVIEW}

\section{A. Malaysian Undergraduates Reading Scenario}

The undergraduates in Malaysia consist of young adults in Malaysia. Young adults are aged between 18 t0 24 years old that makes up the college students and undergraduates.

Consistently, Malaysian undergraduates' prospects of employment have been unpleasantly marked by their lack of proficiency in English (Malaysia Budget 2015; Human Resources Online, 11 
April 2011).Studies have restated that graduates from Malaysia failed meeting the industry standards with one of the main reason that is incompetence in the English language (9); (10). Lack of reading is deemed to be one of the factors of unemployment among graduates. According to Rofiza and Hanani (11), students faced difficulty in utilizing cognitive elements in reading such as understanding, extracting and organizing main ideas, and drawing inferences from their assigned expository texts in the tertiary level. The ability to comprehend a text requires an equitable knowledge grammar, an recognizing main ideas in the text, discourse structure, and strategic processing with more difficult texts. As such, by not mastering such skills, graduates are unable to think critically as part of the industry requirement for a job prospect. Adding to this predicament, a research done on perception of ESL Reading in $i$-Class among Universiti Teknologi MARA Malaysia (UiTM) by Nor Fazlin, Darus (12) revealed that ESL reading among students was regarded as an activity done by students in isolation or on their own and preference of reading texts from examination papers to prepare themselves for examinations. The study further elaborated that students lacked vocabulary and structure of the language and needed reading aids like a dictionary to assist comprehension. This study further strengthens the issue of graduates should not be dependent on learning facilities but learn on ways to improve their reading themselves.

\section{B. Reading Motivation in Second Language Acquisition.}

Guthrie, Hoa (13) describe reading motivation as the one's personal goals, values, and beliefs about the topics, processes, and outcomes of reading. Reading motivation is a complex structure that includes reading goals, intrinsic and extrinsic motivation, self-efficacy and social motivation for reading This framework can be summarized in the chart below.

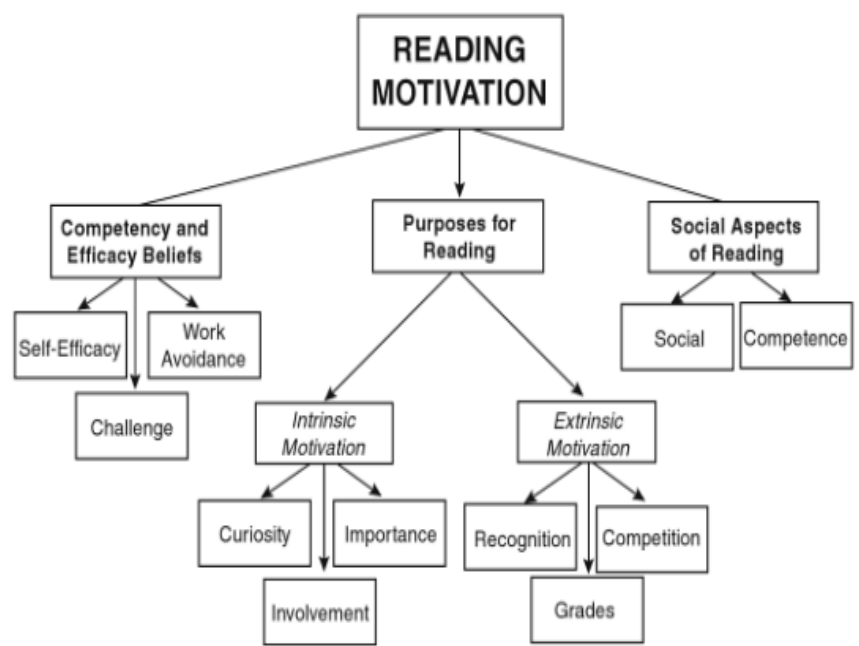

Chart 1: Reading Motivation Framework by Guthrie, Hoa, Wigfield, Tonks, and Perencevich (2005)

From the chart Guthrie, Hoa, Wigfield, Tonks, and Perencevich (2005) (14) outline three important domains that affect reading motivation. These domains are the competency and efficacy beliefs, the purposes of reading and the social aspects of reading. The first domain, which is competency and belief underlies self-efficacy, work avoidance and challenges of the readers. Self -efficacy as suggested by Bandura (1986) in Wigfield and Guthrie (14) is the result related to a task. In addition, researches discovered that social experiences is a powerful tool in the progress of self-efficacy. Teachers and peers beliefs and behaviors are important in creating the self-efficacy of readers. The second domain is the purposes of reading where intrinsic and extrinsic motivation is being outlined. The readers' motivation determines the purpose of reading whether it is for pleasure or grades. Ryan and Deci (2000) defined intrinsic motivation as an activity for the interest, enjoyment, and pleasure as such, it is related to the readiness of experiencing and exploring new ideas, risk-takers, and continuous expanding the potential of readers. Intrinsic motivation may be inhibited, among other things, by social pressures to perform actions that are uninteresting. In contrast, intrinsic motivation is associated with tasks to achieve an external reward. Extrinsic and intrinsic motivation depend to each other as a continuum. These two motivation changes behavior, including persistence levels. Wang and Guthrie (2004) defined similar definition of intrinsic and extrinsic motivation.

\section{Second Language Acquisition Studies in Reading Motivation}

In second language acquisition (SLA), there were not many researches carried out on reading and motivation. Crookes and Schmidt (15) lined out the social psychological approaches for second language motivation. Dörnyei (16) integrate this approach to a three-tiered framework consisting of an integrative instrumental subsystem. This subsystem consists of four conditions that have been adopted in instructional design by using Keller (17) ARCS model of motivation. The ARCS Model of motivation describes students' motivation in terms of attention, relevance, confidence, and satisfaction. Cox and Guthrie (18)further developed an instructional motivational survey based on second language acquisition. Motivational research in SLA has most often covered a general domain that of the learner's motivation. The present study is specifically concerned with the motivation of reading in L2. Currently, there has been an increased interest in extensive reading. Extensive reading (ER) defined by Matthew (19)is reading a large number of easy texts outside of classroom learning as a method to promote reader's fluency, vocabulary acquisition, and good reading habits. ER has shown a positive correlation in learners' gain such as in listening, grammar, vocabulary and oral production. Although ER has been a way to promote reading in L2, not many studies have been conducted in terms of the relationship between motivation and reading in SLA.

Motivation has been an essential factor for second language learners. There were extensive studies done by researchers and variety of theoretical approaches and traditions (Deci \& Ryan, 1985; Dornyei, 2001, 2003;"Gardner 1985, 1996; MacIntyre et al., 2002; Weiner, 1992). Mori (20) conducted a survey of 447 college students of non-native speakers in Japan. These students were selected and given the research motivation questionnaire (RMQ) and results yielded

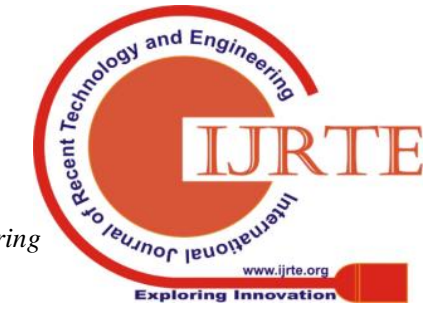


students of were motivated in the intrinsic value of reading, extrinsic utility value of reading, the importance of reading and reading efficacy. Mori (21) conducted the same study on 100 college EFL students in Japan which resulted in higher motivational constructs in intrinsic value, attainment value, and negative intrinsic value in novels. Apple (2005) carried out an extensive study on the motivational constructs in reading among 85 college EFL students in Japan. He administered the RMQ and sought motivation on five constructs which were instrumental orientation, attitudes towards L1 reading, interest in L2 language and culture, language learning beliefs and attitudes toward L2 study. In 2007, Takase carried similar research among 219 high schools of EFL students in Japan which resulted in 6 reading motivation that were being identified. There was intrinsic motivation in L1 and L2 reading, parents' involvement in family attitudes toward reading, entrance-exam and related extrinsic motivation, fondness for written materials and internet related instrumental motivation and negative attitude toward extensive reading. On a recent note, Lin, Wong (22) identified eight reading motivation that constructs in L2 reading. It was listed as self-efficacy, curiosity, involvement, recreation, grade, instrumentalism, social- family and peers. As such study being carried out in L2 readers, the Research Motivational Questionnaire yielded interesting data that emerges in intrinsic and extrinsic motivation where reading materials in L2 played a role in the motivation constructs.

Theoretically, factors that underlie motivation may include goals, intrinsic and extrinsic motivation, values, self -efficacy, and social aspects (Guthrie \& Wigfield, 2000). Much of the research in both L1 and L2 have concentrated on identifying what factors work together or separately to motivate readers. Intrinsic and extrinsic motivation seems to be established as the core factors, while sub-factors would show slight contextual variations. By focusing on cognitively driven aspects of motivation, past studies have contributed valuable insights into the psychology of reading. However, reading is not just a cognitive process, but an activity that is linked to social groups and cultural practices (Wigfield, Eccles, Schiefele, Roeser, \& Davis-Kean, as cited in Huang, 2013). Many readers find the common interest of reading to be socially accepted in their groups.

\section{RESEARCH QUESTION}

The following research studies have been the framework for the present study. This study aims at gathering preliminary data for determining SLA Reading motivations among young adult learners. Hence, the study tested the reliability of the questionnaire as well as analyzing the gathered data. Thus, the research questions are as follows;

1. What is the reliability of RMQ among young adult readers?

2. What are the constructs of reading motivation among Malaysian undergraduates?

Therefore, in an attempt to boost the reading among UiTM undergraduates, an extensive reading course was introduced in their English Language Course. Reading materials from various sources were selected as part of the course. The course aimed at exposing students to extensive reading strategies in order to create enjoyable reading experiences outside the classroom and to enrich and strengthen their knowledge of words. Apart from that, this course aims to raise their proficiency to a high intermediate level by exploiting a variety of materials in varied situations.

\section{METHODOLOGY AND RESEARCH DESIGN.}

Reading Motivation Questionnaire (RMQ) is a psychological test designed by Wigfield and Guthrie (23) to assess one's extent of intrinsic and extrinsic motivation to read the books. The motivation reading questionnaire was given as a pilot study to 68 undergraduates from the engineering and hotel management faculties in University Technology MARA Penang who underwent the reading course for the semester. Their age ranged from 18 to 21 years old. Students who signed up for this course were required to read printed reading materials of selected stories from 12 local writers in Malaysia. Stories were from various Malaysian writers with different themes for each week. The length of the story is for one-sitting of reading, probably less than half an hour to complete the story. The questionnaires were administered during the end of the course with the objective of validating the questionnaire and to establish their initial motivation towards reading. Students were asked to write their views of the stories read and being graded for the course. They were asked to submit reading $\operatorname{logs}$ twice in the semester.

Reading Motivation Questionnaire (RMQ) based on Takase and Otsuki (24) study on Reading Motivation among Japanese's learners were adapted and used in this study. The questionnaire includes 53 statements. Respondent is to choose only one statement. Each statement is related to one of the elements of reading motivation. The lowest score for each dimension is 0 and the highest score is 4 . It takes approximately half an hour to answer all the questions. The questionnaires were posted at the end of the course. The response format for the above items is $1=$ very different from me to $4=$ a lot like me. Scores are computed for each aspect and constructed by averaging across their respective items. The revised MRQ contains 53 items intended to reflect 11 constructs of reading motivation.

The 53 statements were ordered accordingly to the elements of intrinsic and extrinsic motivation that reflects the 11 constructs of reading motivation.

Below are the definitions of eight constructs by Komiyama (25) in Wigfield and Guthrie (26) and WANG and Guthrie (2004)

TABLE 1: Definitions Of EIGHT CONSTRUCTS By KOMIYAMA (2013) IN WIGFIELD (1997) AND WANG AND GUTHRIE (2004).

\begin{tabular}{lll}
\hline $\begin{array}{l}\text { Dimension } \\
\text { of Reading } \\
\text { Motivation }\end{array}$ & Definition & $\begin{array}{l}\text { Theoretical } \\
\text { Concept }\end{array}$ \\
\hline
\end{tabular}




\begin{tabular}{|c|c|c|}
\hline Curiosity & Desire to learn & $\begin{array}{l}\text { Intrinsic } \\
\text { Motivation }\end{array}$ \\
\hline Involvement & Pleasure gained from reading & $\begin{array}{l}\text { Intrinsic } \\
\text { Motivation }\end{array}$ \\
\hline $\begin{array}{l}\text { Preference } \\
\text { for challenge }\end{array}$ & $\begin{array}{l}\text { Satisfaction from mastering or } \\
\text { assimilating complex ideas in } \\
\text { text }\end{array}$ & $\begin{array}{l}\text { Intrinsic } \\
\text { Motivation }\end{array}$ \\
\hline Competition & $\begin{array}{l}\text { Desire to read outperform others } \\
\text { in reading }\end{array}$ & $\begin{array}{l}\text { Extrinsic } \\
\text { Motivation }\end{array}$ \\
\hline Compliance & $\begin{array}{l}\text { Desire to read because of an } \\
\text { external goal or requirement }\end{array}$ & $\begin{array}{l}\text { Extrinsic } \\
\text { Motivation }\end{array}$ \\
\hline Grades & $\begin{array}{l}\text { Desire to receive good grades } \\
\text { and to be favorably evaluated by } \\
\text { the teacher }\end{array}$ & $\begin{array}{l}\text { Extrinsic } \\
\text { Motivation }\end{array}$ \\
\hline Recognition & $\begin{array}{l}\text { Gratification from receiving } \\
\text { recognition for success in } \\
\text { reading }\end{array}$ & $\begin{array}{l}\text { Extrinsic } \\
\text { Motivation }\end{array}$ \\
\hline $\begin{array}{l}\text { Social } \\
\text { Sharing }\end{array}$ & $\begin{array}{l}\text { Satisfaction from sharing the } \\
\text { meanings gained from reading } \\
\text { with peers. }\end{array}$ & $\begin{array}{l}\text { Extrinsic } \\
\text { Motivation }\end{array}$ \\
\hline
\end{tabular}

\section{RESULTS}

The first research question is to test the reliability of the questionnaire or MRQ. This test is conducted to ensure that the questionnaire is trustworthy in gathering the intended data. The questionnaire has 11 elements and each element has a range of 2 to 7 questions. Below is a summary of the reliability of the MRQ.

TABLE 2: SUMMARY OF THE RELIABILITY OF THE RMQ

Cronbach's

Element

$\begin{array}{lll}\text { No. of } & \begin{array}{l}\text { Cronb } \\ \text { ach's }\end{array} & \begin{array}{l}\text { Alpha based } \\ \text { on }\end{array} \\ \text { Items } & \begin{array}{l}\text { Alpha } \\ \text { standardized } \\ \text { items }\end{array} \\ & & \end{array}$

1. Reading Efficacy $\quad 3 \quad 0.73 \quad 0.73$

2. Reading Challenge

$5-0.62$

0.73

3. Reading Curiosity

0.62

0.61

4. Reading Involvement

$6 \quad 0.78$

0.78

$6 \quad 0.86$

0.86

5. Importance of Reading

20.66

0.66

6. Reading Work Avoidance

0.65

0.65

7. Competition in Reading

$6 \quad 0.69$

0.69

8. Recognition for Reading

0.83

0.83

9. Reading for Grades

10. Social Reasons for

0.68

0.68

$7 \quad 0.86$

0.86

reading

11. Reading Compliance

$5 \quad 0.78$

0.78

Test of reliability for reading motivation questionnaire (RMQ) of 68 students within 4 months interval ranged from 0.62 to 0.86 which are higher than 0.5 Cronbach Alpha. The closer the reliability to 1 , the higher is the reliability. The lowest reliability is 0.62 which is Reading Challenge. From the table, the lowest items based on the Cronbach alpha were those belonging to intrinsic motivation dimension as a reading challenge,

The second research question answers to what constructs of reading motivation among the undergraduates, an analysis of score from the reading motivation questionnaire were administered. The lowest score of items pertained to Intrinsic Motivation where students least to agree with the statements such as I enjoy reading good, long stories in English, I like talking with my friends about what I read in English, my friends and I like to share what we read in English, I like challenging English readings and I enjoy telling my friends about the materials I read in English.

From the questionnaire items, the highest mean scores were recorded on the extrinsic Test items. The students scored the highest, thus agreeing with the statement such as when the topic is interesting, I am willing to read difficult English materials, I try to read in English because I need a good score on my English tests, I practice reading in English because I need to do well in my future classes, I want to read in English to improve my grades and I like my instructor to say that I read well in English.

Below is the mean rating recorded according to the 11 dimensions of reading motivation.

TABLE 3: DesCRIPTIVE STATISTIC FOR READING MOTIVATION AMONG YOUNG ADULTS

\begin{tabular}{lccc}
\hline Element & $\begin{array}{c}\text { No. of } \\
\text { Items }\end{array}$ & Mean & $\begin{array}{c}\text { Std. } \\
\text { Dev. }\end{array}$ \\
\hline 1. Reading Efficacy & 4 & 1.80 & 0.38 \\
2. Reading Challenge & 4 & 1.61 & 0.35 \\
3. Reading Curiosity & 4 & 1.98 & 0.43 \\
4. Reading Involvement & 5 & 1.34 & 0.24 \\
5. Importance of Reading & 3 & 1.94 & 0.54 \\
6. Reading Work Avoidance & 5 & 1.26 & 0.11 \\
7. Competition in Reading & 4 & 2.15 & 0.42 \\
8. Recognition for Reading & 4 & 2.10 & 0.40 \\
9. Reading for Grades & 3 & 2.18 & 0.44 \\
10. Social Reasons for reading & 5 & 2.13 & 0.41 \\
11. Reading Compliance & 4 & 1.88 & 0.39 \\
12. Intrinsic motivation (Dimension & & 3.44 & 0.42 \\
2-4) & & & \\
13. Extrinsic motivation (Dimension & & 3.08 & 0.39 \\
7-11) & & & \\
\hline
\end{tabular}

Table 3 shows the mean levels of Intrinsic and Extrinsic of English reading motivation among the students. A higher level of overall extrinsic motivation was discovered in this finding compared to intrinsic motivation.

\section{CONCLUSION AND SUGGESTION}

The findings yielded the results of intrinsic motivation is to be slightly lower compared to extrinsic motivation. Intrinsic motivation seems to dwindle as readers' age. This is supported by studies from Clark and Rumbold (27) that the amount of reading decreases with age.

Nonetheless, it is vital to increase the intrinsic aspect of reading as it will create enjoyment and satisfaction towards reading. Thus, helping second language young adults to improve their ESL proficiency by continuing acquiring the language even outside the borders of the classroom and curriculum.

On the other hand, the extrinsic aspects of reading were shown to play a more important role, which is unlike past studies of Mori (2005). It seems that young adults are

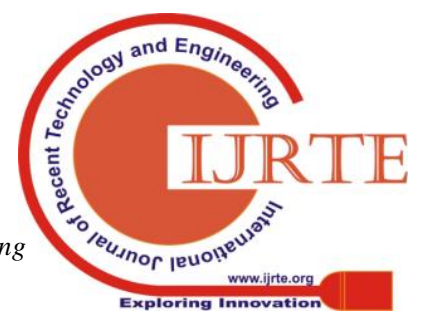


easily motivated to read by giving out rewards and grades, thus making young adult readers to be motivated in reading for the sake of grades, instead of pleasure. It is therefore seen as vital for teachers or academicians to cultivate love or pleasure for reading in order to create proficient graduates for the $21^{\text {st }}$-century working industry. Thus, factors that appeared to encourage reading motivation amongst young adults need to be considered. With the assistance of technology, factors like introducing transmedia reading, digital storytelling that is easily accessed over the internet where opportunities to select online or interactive books, familiarity with books, and social media interactions with others about books should be considered to the young adults of this generation.

\section{ACKNOWLEDGMENT}

This research was supported by the Institute of Quality and Knowledge Advancement (InQKA) Universiti Teknologi MARA Pulau Pinang.

\section{REFERENCES}

[1] Zurina K. A Study of Students' Reading Interests in a Second Language. International Education Studies. 2013;6(11):160-70.

[2] Martinez Marrero L. Reading attitudes, habits and performance of third grade ESL students participating in a reading challenge program 2009.

[3] Tan D, Pandian A, Jaganathan P. Encouraging ESL/EFL reading among lower proficiency students at the tertiary level: The use of graded readers. The Reading Matrix: An International Online Journal. 2016;16(2):20-36.

[4] Abidin MJZ, Pour-Mohammadi M, Alzwari H. EFL students' attitudes towards learning English language: The case of Libyan secondary school students. Asian social science. 2012;8(2):119.

[5] Shahriza Abdul Karim N, Hasan A. Reading habits and attitude in the digital age: Analysis of gender and academic program differences in Malaysia. The Electronic Library. 2007;25(3):285-98.

[6] Pandian A, editor A study on readership behaviour among multi-ethnic, multi-lingual Malaysian students. 7th International Literacy and Education Research Network (LERN) Conference on Learning, RMIT University, Melbourne, July; 2000.

[7] Musa NC, Lie KY, Azman H. Exploring English language learning and teaching in Malaysia. GEMA Online ${ }^{\circledR}$ Journal of Language Studies. 2012;12(1).

[8] Nik YA, Zakaria F, Hamzah A, Hasbollah HR. Reading motivation and reading strategies employed by undergraduates in a public university in Malaysia. 2012

[9] Burns MK, Kwoka H, Lim B, Crone M, Haegele K, Parker DC, et al. Minimum reading fluency necessary for comprehension among second-grade students. Psychology in the Schools. 2011;48(2):124-32.

[10] Ambigapathy P, Aniswal A. University curriculum: An evaluation on preparing graduates for employment. Higher Education Research Monograph. 2005;6:2005.

[11] Rofiza AB, Hanani AZ, editors. What good is digital storytelling? The case of cognitive Reading Responses between Two Readers. International Conference on Economics, Education and Humanities, Bali, Indonesia; 2014.

[12] Nor Fazlin MR, Darus S, Bakar NA. Metacognitive online reading strategies of adult ESL learners using a learning management system. Theory and Practice in Language Studies. 2011;1(3):195-204.

[13] Guthrie JT, Hoa LW, Wigfield A, Tonks SM, Perencevich KC. From spark to fire: Can situational reading interest lead to long-term reading motivation? Literacy Research and Instruction. 2005;45(2):91-117.

[14] Wigfield A, Guthrie JT. Engagement and motivation in reading. Handbook of reading research. 2000;3:403-22.

[15] Crookes G, Schmidt RW. Motivation: Reopening the research agenda. Language learning. 1991;41(4):469-512.

[16] Dörnyei Z. Motivation and motivating in the foreign language classroom. The modern language journal. 1994;78(3):273-84.

[17] Keller JM. Development and use of the ARCS model of instructional design. Journal of instructional development. 1987;10(3):2.
[18] Cox KE, Guthrie JT. Motivational and cognitive contributions to students' amount of reading. Contemporary Educational Psychology. 2001;26(1):116-31.

[19] Matthew T. Extensive reading and the motivation to read: A pilo study. Doshisha Studies in Language and Culture. 2005;8(1):193-212.

[20] Mori S. Redefining motivation to read in a foreign language. Reading in a Foreign language. 2002;14(2):91.

[21] Mori S. Significant motivational predictors of the amount of reading by EFL learners in Japan. RELC Journal. 2004;35(1):63-81.

[22] Lin D, Wong KK, McBride-Chang C. Reading motivation and reading comprehension in Chinese and English among bilingual students. Reading and Writing. 2012;25(3):717-37.

[23] Wigfield A, Guthrie JT. Relations of children's motivation for reading to the amount and breadth or their reading. Journal of educational psychology. 1997;89(3):420.

[24] Takase A, Otsuki K. New challenges to motivate remedial EFL students to read extensively. Apples-Journal of Applied Language Studies. 2012.

[25] Komiyama R. Factors underlying second language reading motivation of adult EAP students. Reading in a Foreign Language. 2013;25(2):149-69.

[26] Wigfield A, Guthrie JT. Motivation for reading: An overview. Educational Psychologist. 1997;32(2):57-8.

[27] Clark C, Rumbold K. Reading for Pleasure: A Research Overview. National Literacy Trust. 2006. 